\title{
An Exploratory Study of Consumer Satisfaction and Purchase Behavior Intention of Fashion Subscription- Based Online Services (SOS)
}

\author{
Erica E Spurgeon ${ }^{1}$ and Linda S Niehm ${ }^{2 *}$ \\ ${ }^{1}$ Fashion and Apparel Merchandising, University of Central Missouri, USA \\ ${ }^{2}$ Department of Apparel, Events, and Hospitality Management, Iowa State University, USA
}

*Corresponding author: Linda S Niehm, Department of Apparel, Events, and Hospitality Management, Iowa State University, USA.

Received Date: February 14, 2020

Published Date: February 26, 2020

\begin{abstract}
Subscription-based online services (SOS) that provide fashion related products are of great interest to consumers and retailers alike. Yet, little is known about consumers who use or have used SOS. This study explored consumers' motivations, expectations, satisfaction, and purchase behavior intentions regarding fashion SOS using an Expectation-Confirmation Theory (ECT) perspective. A qualitative research approach was utilized to collect interview data from a sample of 12 SOS customers. Findings revealed that consumers' motivations to try fashion SOS were related to convenience, needing a wardrobe update, and curiosity about the service. Only five out of 12 participants were completely satisfied with fashion SOS that they used, and those participants agreed to receive a scheduled box delivery each month. Consumers liked the convenience of fashion SOS package delivery and ease of website navigation. They were much less satisfied with their fashion SOS experience in terms of the delivered product selection and product quality. Recommendations are provided for retailer competitive strategies with SOS business models and future research suggestions are proposed.

Keywords: Fashion, Subscription-box Online Service, Online Subscription, Satisfaction, Confirmation, Expectation, Purchase Behaviors, Purchase Intentions, Expectation-Confirmation-Theory
\end{abstract}

Abbreviations: SOS- Subscription-box Online Service; ECT- Expectation-Confirmation Theory

\section{Introduction}

A subscription-based service (SOS) is an online business where the company sends the customer a customized box periodically, for a weekly or monthly fee [1]. This business model is not exactly a new business concept, as some have been around for decades (e.g., Wine-of-the-month Club and Columbia House CD Club) [2]. However, with the increased use of e-commerce and mobile shopping, companies like Birch Box, Hello Fresh, Ipsy, and Dollar Shave Club have adopted this business model allowing new ways for consumers to purchase their products [3].

Consumers can purchase from approximately 2,000 different SOS businesses [2], including product categories such as beauty, apparel, pets, kids, food, beverage, art, and lifestyle products $[4,5]$. Retail analysts' project that SOS will soon be just another ordinary business channel like e-commerce and brick-and-mortar [2]. However, it is unknown if fashion retailers and e-commerce leaders realize the true potential of what this model can do for their businesses. Roussin I [3] stated, "when a subscription commerce model is implemented successfully, it can boost revenue, enhance customer loyalty, bring in new customers and position the brand as a disruptor in the market."

Although SOS is a trending topic, few researchers have addressed this business model. Extant research has focused on understanding who the fashion SOS customer is [1], the consumer's 
perception of this retail format [6], variables that influence consumer attitude towards fashion SOS [5], and consumer adoption intention $[5,6]$. However, there is a need to investigate consumers who have already used SOS and establish an understanding of their satisfaction and purchasing behavior intentions. Therefore, the main purpose of this study is to explore customer satisfaction and purchase behavior intentions concerning fashion SOS. Following the Expectation-Confirmation Theory (ECT) [7], this qualitative study addressed the following research questions:

RQ1: What are consumers' motivations to try a fashion SOS?

RQ2: Are customers of fashion SOS satisfied with their experience based on ECT?

RQ3: What are the purchase behaviors and intentions of fashion SOS consumers?

In order for this business model to be sustainable in the highly competitive fashion market, retailers must understand more fully who is subscribing to fashion SOS, consumers' thoughts about their experience, and if consumers are satisfied or not. Overall, why consumers choose to cancel their fashion SOS or continue to proceed with it, customer satisfaction, purchase behaviors and intentions pertaining to fashion SOS all warrant further examination. The results of the study will not only fill a literature gap regarding consumer satisfaction with fashion SOS but will also provide fashion business leaders with valuable insight to further develop their business model.

The following literature review will discuss the SOS business model, including three types of SOS. Research related to consumer satisfaction with e-service quality will also be presented, along with information on SOS product evaluation criteria and ECT.

\section{Literature}

\section{Subscription-based online services (SOS)}

According to Chen T, et al. [8], there are three types of SOS model variations: replenishment, curation, and access subscriptions. In replenishment subscriptions, consumers choose to purchase more simple products that do not change month-to-month in order for them to save money and time (e.g., Amazon Subscribe \& Save and Quip). This subscription model would be a more "traditional" approach where people pay a monthly fee for items such as newspapers and magazines [9]. In this model, there is typically no styling service fee.

Curation subscriptions, such as Stitch Fix and Trunk Club, are customized and created by a stylist to fit the needs and wants of the consumer. Consumers do not choose their particular items or see all product offerings, like with other types of subscription services. These curated services typically have some kind of styling fee but are by far the most popular type of subscription box service [8]. The main reason for this popularity is that consumers like the surprise factor [1]. This type of service does not have to be a "subscription" or have a commitment-based approach [9], as some allow you to skip an order as desired or preset a preferred timeframe of shipments.

In access subscriptions, members pay to obtain exclusive benefits such as lower prices and membership perks (e.g., JustFab \& Thrivemarket). Compared to replenishment and curation, access subscriptions are the least like a "traditional" subscription service. Amazon, for example, offers perks to only their Amazon Prime Members (e.g., Amazon Prime Wardrobe). The company allows their members to see what they offer and then ship the products with no obligation to buy [6].

\section{Fashion SOS}

Due to the ever-changing and competitive fashion retail market, fashion companies must adopt to consumers' lifestyles and product preferences. Fashion companies, such as Stitch Fix, Le Tote, Shoe Dazzle, Fabletics, Wantable, and Trunk Club, are only some of the many that have adopted the SOS model. Fashion SOS can follow either the curation or access subscription service approach [8] and can have several unique characteristics, which may include customized selected products, customer association or membership, and a home try-on experience [6]. Most fashion SOS companies sell fashion products including apparel, footwear, and accessories.

\section{Consumers of fashion SOS}

Consumers who purchase SOS are not only willing to purchase unfamiliar products, but also allow strangers to pick out products and curate the package for them [2]. Woo $\mathrm{H}$, et al. [1] research addressed consumers of fashion SOS businesses. They found that most fashion SOS consumers were female and had a high level of fashion consciousness, as well as high level of e-trust. Chen et al. [8] found similar results, stating that SOS subscribers tended to be younger (25-44) and female. The subscribers lived in more urban environments with income levels from $\$ 50,000$ to $\$ 100,000$.

Woo $\mathrm{H}$, et al. [1] emphasize that the shopping experience is different for the SOS consumer. They describe that the SOS consumer does not need to go through stages of product/trend information search, evaluation of alternatives, or product choice. Instead, the fashion SOS has a curator or stylist select the items for the consumer, bundle items in a box, and deliver the selection to the consumer's front door. The authors discuss that the fashion SOS model resolves modern consumer "decision fatigue", created by extensive searching on the web to find the right styles or prices, or even making multiple shopping trips to the local mall.

Tao Q, et al. [6] found that there is limited knowledge concerning the services offered by fashion SOS. They also discovered that although consumers do not know much about the services, they perceive strong relative advantages, such as convenience, personalization, consumer excitement, opportunities to try new styles, and opportunity for budget management.

Ramkumar B, et al. [5] work revealed that consumers' hedonic 
and utilitarian motivations, as well as high online transaction selfefficacy, positively influenced their attitude toward the SOS service. Based on these findings, consumers had greater intentions to use fashion SOS. Although research indicates baseline information about who the consumers of fashion SOS are, questions remain regarding SOS user profiles and shopping behaviors, their motivations to buy, and what fashion SOS companies they prefer.

\section{Consumer satisfaction with e-service and product evaluation criteria}

E-Service quality: E-service quality is the consumer's perceived experience of performance related to service provided in an online setting [10]. The service provided by fashion SOS businesses could be everything from ease of website use, to delivery response time. If consumers are not satisfied with the initial e-service that they are provided with (e.g., profile quiz and ease of use of website or app), they may expect the end of their service (e.g., receiving the product and choosing what they want to keep) to be disappointing as well. This scenario may deter the consumer from purchasing products that are shipped a few days after their first initial touchpoint. Based on prior research, this thought sequence is similarly reflected with repeat purchase intentions $[7,11,12,13]$. It is therefore plausible that consumers' perceived satisfaction with fashion SOS e-service quality may impact their desire to receive future subscription boxes.

Prior research regarding e-service quality reveals that consumers place importance on dimensions such as responsiveness, service reliability, competence, ease of use, and systems reliability [14]. Another study [15] focused on increasing website viewing rates and customer preservation, resulted in a conceptual model based of e-service quality elements. In the apparel industry context, researchers reviewed online retailer's websites when looking at the construct of e-service quality [16]. They found that shoppers perceived website quality based on website appearance and visual elements, entertainment factors, informational fit-to-task, transaction capability, response time, and trust. Pertaining to the SOS business model, no prior research has examined the effect of e-service quality on satisfaction, which may consequently lead to repurchase intention.

Product quality evaluation criteria: Satisfaction with product quality is an important attribute to SOS businesses. If consumers are not satisfied with the items that they receive, and do not purchase anything, they are less likely to subscribe again [7]. This can be a challenge to fashion SOS businesses, because they thrive on anticipating continual consumer demand [8]. Chen et al. [8] describe, "the higher the churn rate, the more difficult it becomes for subscription e-commerce companies to cover their acquisitions costs and to scale their revenues."

Product quality criteria has been widely investigated in the realm of clothing and fashion products. Consumers look at elements such as aesthetics, usefulness, performance/quality, and extrinsic criteria when purchasing products from a physical store [17]. Abraham-Murali L, et al. [18] found similar results, noting that consumers evaluate purchased apparel by physical appearance, physical performance, expressive, and extrinsic criteria. More recent evidence [19], explained the rental apparel evaluative criteria included fit, garment styling, social feedback, appropriateness, color and pattern, fabric, and physical comfort. Pertaining to SOS product quality, no research to date has addressed consumer satisfaction with the products or criteria they apply when making assessments.

\section{Theoretical framework: Expectation-Confirmation Theory}

The present research draws from Oliver R [7] ECT to understand consumers' satisfaction with fashion products purchased through SOS. The key components of the ECT include expectation, confirmation, and satisfaction. ECT postulates that prior to an event, a consumer has expectations for the forthcoming experience. If that expectation is met in a positive manner (e.g. confirmation), the customer is satisfied $[7,11,13]$. When expectations are not met (e.g. disconfirmation), the consumer may logically be dissatisfied. Oliver $\mathrm{R}$ [7] offers that the consumer should reach the stage of repurchase intention if the expectation-confirmation-satisfaction sequence is fulfilled (Figure 1).

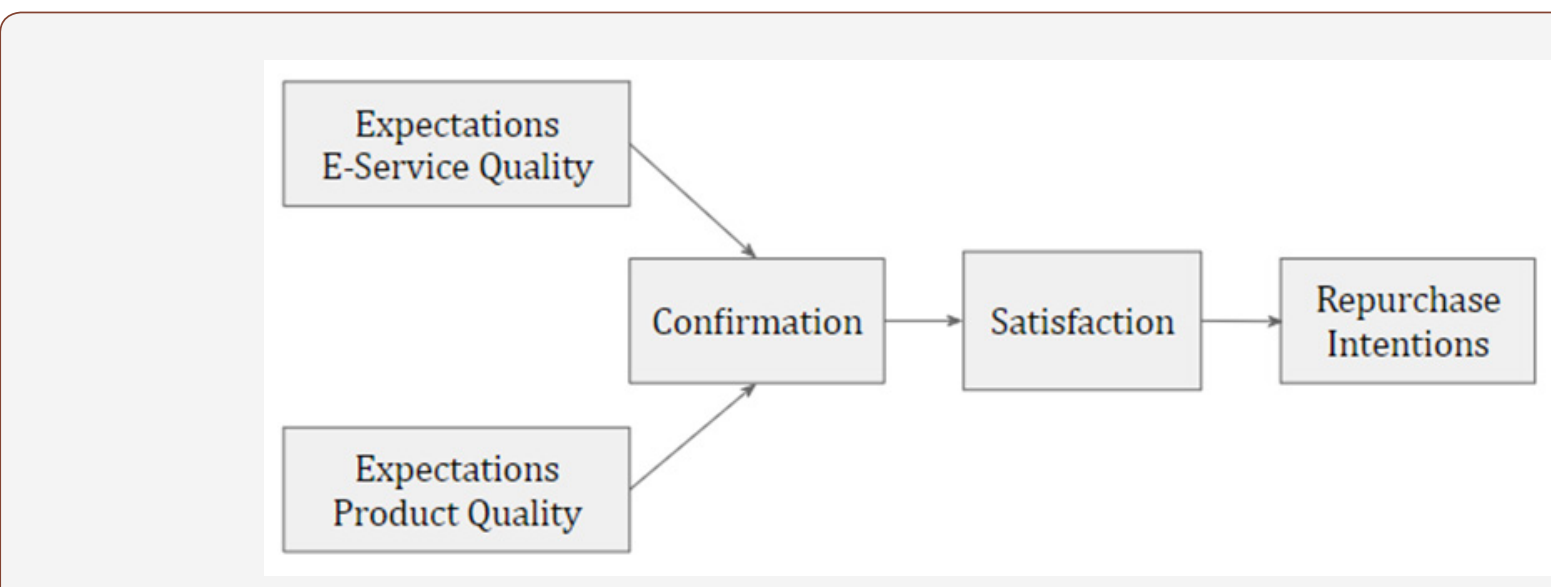

Figure 1:Fashion SOS Expectation-Confirmation-Satisfaction Model adapted by Oliver R [7]. 
Expectations: According to Churchill G, et al. [12], satisfaction is defined as the end-result after comparing costs and rewards of the purchase in relation to expectations. Consumer satisfaction is based on positive expectations, according to the ECT $[7,11,13]$.

As for the fashion SOS consumer, they may have an initial expectation for the service, which may be formed by things they observed on the company website, experiences they previously had, or word-of-mouth comments from a friend that just received a subscription box. The consumer may sign up for the box service by filling out a style profile on the business's website or app and is typically charged a fee if curation is included. In the following days, the consumer receives a box of fashion items and they choose what they want to keep. If the consumer chooses to return items to the SOS, they do so in a pre-labeled bag that the SOS provides. The only items for which consumers are charged are the ones they keep. They are also assessed a styling fee for their purchase. After the service is complete for a given month, consumers form perceptions about what they should have experienced. Once customers assess their experience against the actual service performance, expectations are confirmed or disconfirmed. Researchers have not to date investigated the expectations of consumers concerning fashion SOS.

Confirmation: Prior research describes disconfirmation as the "crucial intervening variable" [12] in satisfaction research. It is described as the variance "between prior expectations and the actual performance" [12]. Consumers' expectations are confirmed when a product/service performs as they expected [12]. When the product/service performs worse than expected, negative disconfirmation takes place; positive disconfirmation is when the product/service performs better than expected [12]. When confirmation transpires in consumers' fashion sOS experience, the level of satisfaction is affected [20].

Satisfaction and purchase behavior intention: Purchase behaviors, like buying decisions of the fashion SOS consumer [1], are different online versus in store. The SOS consumer first makes the decision to sign up for the service. The next decision step takes place when the subscription box arrives. The consumer reviews the garments received and decides if they want to purchase them. If the consumer is satisfied with the quality of e-service and product, they decide if they want to subscribe again the next month, three months out, six months out, or never. Questions remain, however, concerning SOS consumers' decision process, resulting satisfaction, and purchase/repurchase intentions. The present qualitative study explores this decision process and attempts to add deeper understanding of the SOS consumer.

\section{Method}

Prior to conducting the interviews, Institutional Review Board (IRB) approval was obtained from the researchers' university. In order to gain rich, in-depth knowledge of SOS consumers' motivations, expectations, satisfaction, and purchase intentions, qualitative methods were employed [21]. A purposive sampling technique was to identify 12 participants who had used SOS services. All participants were female fashion SOS consumers, identified via Facebook through multiple posts concerning their experiences. The lead researcher invited potential participants through a personal Facebook page. The post explained the study and extended an invitation to participate in a 30-45-minute interview about SOS experiences. Once the invited participant replied and accepted, an interview was scheduled. Interviews were conducted face-to-face, or by phone, based on participant location and preference.

Prior to the interview, participants were asked to complete a short demographic survey including the following descriptive information: age, ethnicity, highest educational level completed, household income, current employment status, and marital status. An interview protocol developed by the researchers to guide the open-ended interview process [22]. Interviews were guided by Expectation-Confirmation Theory (ECT) and research questions posed for the study. An interview script comprised of 23 questions addressed: consumer background and experience with SOS, expectations they had prior to using SOS, satisfaction with SOS products and service quality, and purchase intentions of the SOS consumer.

Participants were encouraged to freely contribute their thoughts and views about past fashion SOS experiences. The interviews were audio recorded for accuracy, and then transcribed using the Transcribe Me! App. Transcriptions were analyzed using a constant comparison method. Key words or phrases from participants were identified, resulting in emergent themes [21].

\section{Results and Discussion}

All sample participants were female. Age ranges for the participants were $25-34$ (50\%), 35-44 (42\%), and 55 or over (8\%). Most of the participants were White or European American (92\%) or Two or More Races (8\%). None of the participants had less than an associate degree. The household income ranges were $\$ 50 \mathrm{~K}$ \$150K (40\%), \$100K- \$150K (30\%), over \$200K (10\%), \$150$\$ 200 \mathrm{~K}(10 \%)$, and $\$ 10-\$ 50 \mathrm{~K}(10 \%)$. Most of the participants were Employed Full- time (84\%) or a Homemaker (16\%) and were Married (75\%) or Single (never married) (25\%).

Analysis of the interview data resulted in central themes linked to the ECT and provided insight related research questions posed for the study. Participants had tried a variety of fashion SOS services such as Le Tote, Wantable, Adore Me, Stitch Fix, Just Fab and Trunk Club. Some of the participants had used multiple services. Most of participants had learned about the services through social media (e.g., Facebook or Instagram) or by word of mouth from friends or family. Results and related discussion are presented by research question, following the ECT sequence: consumers' motivations, consumers' expectation/confirmation/satisfaction, and consumers' purchase behavior intentions. 


\section{Consumers' motivations (RQ1)}

Convenience: Consumers of fashion SOS are searching for ways to avoid the headache of shopping for fashion related products [23] and enjoy the convenience of someone else doing it for them. Most participants in this study expressed that they live busy lives and would prefer to not spend their leisure time on shopping trips. The convenience of fashion SOS allows consumers a way to manage their time, while someone else selects outfits customized to their tastes and lifestyle. Overall, the participants tried a fashion SOS service to make shopping an easier and obtain a more convenient way to get fashion goods. These motivations are captured in the following quote:

"I tried a subscription box with clothing because I love fashion. I love getting new fun things for my wardrobe, but I hate shopping. I've had a couple of kids and I have my career and my own business. If I see something online that I like, and that's the appeal of the subscription box, I tell my stylist and they send me stuff. It's like shopping from my living room but easier "(P11).

New style ideas: Consumers who purchase SOS are looking for a way to broaden their style horizons, in ways that most brick-andmortar and online shopping sources cannot fulfill. Consumers are looking for age appropriate garments, on trend styles, and provide out of the box wardrobe options. Based on participant responses, some are looking for designer name brand items or items that they would not pick out themselves. A participant described that she not only needed items such as basics, jeans, and outwear pieces, but she also wanted someone to put together her entire look. Not all of the participants were highly involved in fashion and following the latest styles, but they were all open to new wardrobe styling ideas. One participant disclosed how certain fashion SOS companies provided her with new brands that she never had heard of before. These could be brands that are exclusive to the fashion SOS or fashion styles that she cannot purchase in the rural area where she resides. Purchasing unique brands and different style options than those in her small community was an important consideration. Her remark was "I like knowing that not everyone in my community is going to be wearing what I just purchased" (P4).

Curiosity about the service: Consumers are in general very curious about the SOS format. One participant said, "I signed up for the service to just to see what they would pick for me" (P1). Another participant says, "I signed up because others in my office were doing it and everyone thought it would be a fun thing to do together" (P8). Participants are willing to spend the styling fee just to see what the service provides.

Promotional enticement is also a reason consumers in this study were curious about SOS services. Most of the services do some kind of referral program. An example of this Stitch Fix, where consumers invite friends to try the service. If a friend signs up, the consumer gets $\$ 25$ in credit and the friend does too. One participant disclosed that an ad was what brought her to subscribe to a fashion SOS. She says, "Their ads will get me. If I see an ad and the outfit is really cute, I think to myself .... that will be a great going out outfit" (P4).

Some of the participants did mention that they enjoyed the surprise factor of SOS, which is in line with Woo H, et al. [1] findings. It is important for consumers of fashion SOS to know that their package was shipped and to see their package on their doorstep. They anticipate what is in the box and hope that the items are exactly what they are seeking in their wardrobe. Not knowing what is in the package made some fashion SOS consumers' experiences unique and special in contrast to shopping at a brick-and-mortar store.

\section{Consumers' expectation/confirmation/satisfaction (RQ2)}

E-Service quality: Consumers of fashion SOS expected that the service would be easy to navigate using their mobile phone app or desktop computer. This would include good customer service and ease of process (e.g., signing up for the service, check out, package delivery, and exchange/returns). One participant revealed, "It was so easy to use and so convenient for my lifestyle" (P2). Based on the interview data, e-service quality was confirmed by all participants, which lead to satisfaction with basic transactional aspects of e-service quality overall.

Product quality: This study revealed that consumers of fashion SOS have certain product criteria that they tend to use in purchase decisions. Based on the interview findings, participants expected the service to send items with good quality fabrication, appropriate fit, functionality, unique styling details, and comfort. Some participants felt that the product matched their styling profile provided prior to receiving their package. Some participants thought that their SOS boxes were appealing and bought multiple items. However, most did not think that all of the items that the fashion SOS sent matched their style profile or comments given to their stylist. One participant shared:

“They missed the mark. 100\%. It was like they didn't read any of the information that I submitted. They didn't understand what I needed, and I would have bought stuff if they would have done that" (P12).

Multiple participants expressed the need for more personal contact with their stylist. One participant sensed that she was "talking to a machine" (P8) most of the time. Unfortunately, disconfirmation occurred in relation to satisfaction with the product provided in their boxes. Overall, only five out of the 12 participants (42\%) were completely satisfied with their e-service quality and product quality. Most participants had high expectations of the fashion service, especially if it was a curated box, and hoped to receive good quality service as well as quality products in their package. However, their satisfaction was not confirmed with SOS based on their actual experience, particularly regarding product quality and aesthetics. 


\section{Consumers' purchase behavior intentions (RQ3)}

Most participants had purchased at least one item from their SOS box received, but some mentioned that they did so because of the stylist fee that was automatically charged. One participant said, "I felt forced to buy something to not lose out on the \$20 I had already paid" (P7). Another said, "I bought some things that I didn't love, or I wouldn't buy normally" (P10) because of the $\$ 20$ fee. However, a few participants purchased their entire box in order to receive a sizeable discount. Only five out of the 12 participants $(42 \%)$ had agreed to receive a regularly scheduled box from the SOS service they used. The same five participants, that experienced satisfaction in both e-service quality and product quality, agreed to continue their service. These findings suggest that consumer's loyalty to and satisfaction with the fashion SOS are sustainable if expectations, and satisfaction confirmation are reached. If participants experience any kind of disconfirmation, they tend to discontinue their SOS service immediately.

\section{Conclusion}

Guided by the ECT [7], this study explored the following: consumer motivation, expectation, confirmation, satisfaction, and purchase behavior intention concerning fashion SOS. The study was an exploratory attempt to capture ideas and thoughts of SOS consumers regarding their experiences with a fashion SOS services. Analysis of 12 in-depth interviews revealed that female consumers are motivated to subscribe to a fashion SOS due to convenience, desire for new style options, and curiosity of the new business format. All participants interviewed confirmed their expectations for SOS when it came to transactional e-service quality, which would be the ease of process, customer service, returns/exchanges. However, only five out of 12 participants confirmed their expectations and were satisfied with the product criteria quality of fashion goods they received.

Consumers expressed that they were dissatisfied with the SOS product quality based on aesthetics and did not think it matched their style criteria. Overall, not all consumers experienced expectations that lead to confirmation and satisfaction. Based on the findings of this study, female consumers who experienced expectation confirmation, became satisfied and intended to continue their service for the foreseeable future. If they experienced expectations that were disconfirmed, they were likely to quickly discontinued their service subscription.

\section{Implications}

Findings of this research provide a variety of implications for SOS retailers and researchers. While consumers liked the convenience of SOS package delivery and ease of website navigation, they were still not completely satisfied with their current fashion SOS experience in terms of the delivered product selection and quality. Results of the study provide fashion SOS business leaders with insight on how to better serve consumers. This research specifically targets points of satisfaction and dissatisfaction with e-service quality and product quality criteria, so mangers can determine how to possibly modify their procedures or buying processes to enhance the consumer SOS experience. In order for this business model to be sustainable in the highly competitive fashion market, consumers must be satisfied at all levels. Based on results of the present study, fashion SOS companies must invest more in personal interaction to collect accurate customer information and build lasting customer relationships. These steps may enhance loyalty to the brand and greater satisfaction with product quality and styles overall. A key finding of the study is that SOS customers are satisfied with transactions and technical aspects of e-service quality. However, to enhance brand loyalty and ongoing purchase intentions, the SOS fashion sector needs to close the service gap and focus on developing and delivering satisfaction with both e-service quality and product quality. Consumer expectations for product and style quality revealed in this research provide strategic guidance for SOS companies. Listening to customer motivations and expectations may enhance customer satisfaction with their brand and products, and in turn lead to sales and profitability for SOS brands.

Findings of this study can be used in future research to create modified scales of ECT factors for the SOS context. Quantitative studies may examine fashion SOS consumer satisfaction phenomena in greater depth, such as consumer motivations, expectations, loyalty, and repurchase behaviors. Future research could also investigate male fashion SOS consumers and analyze effectiveness of fashion SOS business strategies. This research could also be expanded to include other SOS product categories such as home goods, pet products, and technology items.

\section{Recommendations}

Based on results of this study, several specific recommendations are proposed for fashion SOS companies. Modifications to the fashion SOS model may include allowing for several items (perhaps two to five) to be selected by the consumer for inclusion in the monthly SOS package. The SOS stylist could then complete a look to create a coherent and complete styled assortment. This would give the consumer a chance to actively engage with the brand, select some merchandise, yet still experience the surprise factor and receive novel items they enjoy. This model would reduce the feeling of consumer obligation to purchase items that they had not seen before or did not fit with their expectations and user profile. Since the current fashion SOS business model thrives on repurchase intentions from consumers month to month, this recommendation could provide retailers with a more sustainable revenue stream and profitability from SOS.

\section{Limitations}

Like other studies, this research may present some potential limitations. The first limitation comes from the method of individual qualitative interviews. The information collected may be subject to interpretation bias when transcribing and categorizing 
themes. Another potential limitation is related to participants using different fashion SOS services. This may make it hard to find similar themes patterns in the data. The sample was also limited to female fashion SOS consumers, which is not generalizable to the entire population.

Limited prior studies regarding fashion SOS have identified consumer profiles and attitudes toward the new retail business model. However, little information is known about satisfaction with e-service quality and product quality criteria as well as SOS consumer repurchase intentions. This research provides rich baseline knowledge base of the female fashion SOS consumer and their satisfaction and dissatisfaction points with SOS services. Findings also provides great insight into the SOS business model and potential modifications to enhance consumer satisfaction and business sustainability.

\section{Acknowledgement}

None.

\section{Conflict of Interest}

No conflict of interest.

\section{References}

1. Woo H, Ramkumar B (2017) Who seeks a surprise box? Predictors of consumers' use of fashion and beauty subscription-based online services (SOS). Journal of Retailing and Consumer Services 41: 121-130.

2. Pike M (2016) Will Subscription Services work for Fashion? The Business of Fashion.

3. Roussin I (2016) How subscription commerce is transforming retail. Total Retail.

4. Kestenbaum R (2017) Subscription Businesses Are Exploding with Growth. Forbes.

5. Ramkumar B, Woo H (2018) Modeling Consumers Intention to use Fashion and Beauty Subscription-Based Online Services (SOS). Journal of Fashion and Textiles 5(22): 1-22.

6. Tao Q Xu Y (2018) Fashion subscription retailing: An exploratory study of consumer perceptions. Journal of Fashion Marketing and Management 22(4): 494-508.

7. Oliver R (1980) A Cognitive Model of the Antecedents and Consequences of Satisfaction Decisions. Journal of Marketing Research 17(4): 460-469.
8. Chen T, Fenyo K, Yang S, Zhang J (2018) Thinking inside the subscription box: New research on e-commerce consumers. McKinsey \& Company.

9. Ewen L (2017) Why retailers are going all in on subscription services. Retail Dive.

10. Blut M, Chowdhry N, Mittal V, Brock C (2015) E-Service Quality: A MetaAnalytic Review. Journal of Retailing 91(4): 679-700.

11. Bhattacherjee A (2001) Understanding Information Systems Continuance: An Expectation-Confirmation Model. MIS Quarterly 25(3): 351-370.

12. Churchill G, Surprenant C (1982) An Investigation into the Determinants of Customer Satisfaction. Journal of Marketing Research 19(4): 491-504.

13. Oliver RL (1981) Measurement and Evaluation of Satisfaction Processes in Retail Settings. Journal of Retailing 57(3): 1-25.

14. Yang Z, Fang X (2004) Online service quality dimensions and their relationships with satisfaction: A content analysis of customer reviews of securities brokerage services. International Journal of Service Industry Management (15): 302-326.

15. Santos J (2003) E-service quality: A model of virtual service quality dimensions. Managing Service Quality 13(3): 233-246.

16. Kim S, Stoel L (2004) Apparel retailers: Website quality dimensions and satisfaction. Journal of Retailing and Consumer Services 11(2): 109-117.

17. Eckman M, Damhorst ML, Kadolph SJ (1990) Toward a model of the instore purchase decision process: Consumer use of criteria for evaluating women's apparel. Clothing and Textiles Research Journal 8(2): 13-22.

18. Abraham-Murali L, Littrell M (1995) Consumers' Conceptualization of Apparel Attributes. Clothing and Textiles Research Journal 13(2): 65-74.

19. Mckinney E, Shin E (2016) Exploring Criteria Consumers Use in Evaluating Their Online Formal Wear Rental Experience: A Content Analysis of Online Reviews. Clothing and Textiles Research Journal 34(4): 272-286.

20. Hong S, Thong JY, Tam KY (2006). Understanding continued information technology usage behavior: A comparison of three models in the context of mobile internet. Decision Support Systems 42(3): 1819-1834.

21. Creswell J (2009) Research design: Qualitative, quantitative, and mixed methods approaches $\left(3^{\text {rd }}\right.$ edn). Thousand Oaks: Sage Publications, California, USA

22. Turner D (2010) Qualitative interview design: A practical guide for novice investigators. The Qualitative Report 15(3): 754-760.

23. Smiley L (2019) Stitch Fix's radical data-driven way to sell clothes- $\$ 1.2$ billion last year-is reinventing retail. Fast Company. 